\title{
A mixed methods analysis of EFL teachers' self-regulated strategies and burnout
}

Royaei, Nahid

English Department, Imam Reza International University, Mashhad, Iran (royaei_nahid@yahoo.com)

Ghonsooly, Behzad

English Department, Ferdowsi University of Mashhad, Iran (ghonsooly@yahoo.com)

Ghanizadeh, Afsaneh $\bowtie$

English Department, Imam Reza International University, Mashhad, Iran(ghanizadeafsane@yahoo.com)

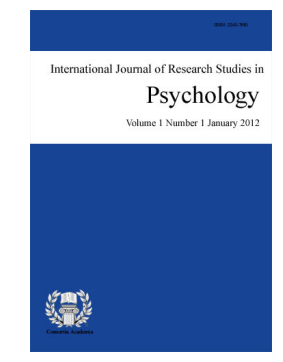

ISSN: $2243-7681$ Online ISSN: 2243-769X

OPEN ACCESS

\section{Abstract}

This study examined the link between self-regulation and burnout depletion among Iranian EFL teachers quantitatively and explored the burnout sources and various patterns of self-regulated strategies in different EFL levels qualitatively. For this aim, a total of 125 English language teachers teaching in various language institutes in Mashhad took part in this study. They completed two questionnaires: Teacher Self-regulation Scale (TSRS) and Maslach Burnout Inventory (MBI). The findings yielded via correlation analysis documented that there was a negative significant relationship between applying self-regulated strategies and burnout depletion. Subsequent data analyses via Stepwise Regression showed that among the components of self-regulated strategies, goal setting was the best predictor of burnout. Results from interview analysis revealed that teachers applied different self-regulated strategies at each level and experienced different burnout sources. The implications were further discussed with reference to earlier findings.

Keywords: teachers' self-regulation; teachers' burnout; correlation; regression; interview 


\section{A mixed methods analysis of EFL teachers' self-regulated strategies and burnout}

\section{Introduction}

Self-regulation has exerted its prominent influence on learning and teaching approaches since mid-1980s (De Corte, Depaepe, Op't Eynde, \&Verschaffel, 2011). Zimmerman (2008) stated that SRL is "the degree to which students are meta-cognitively, motivationally, and behaviorally active participants in their own learning process" (p. 167). It adheres to the constructivist perspective of learning that sheds light on the agentic role of learners (De Corte et al., 2011). This agentic aspect provides human beings who are self-regulated in learning to perform both autonomously and tend to have an effect on their results and experiences (Barnard-Brak, Lan, \& Paton, 2010). From this agentic perspective, the self-regulation of learning is taken into consideration as supporting self-deterministic dimension (Barnard-Brak et al., 2010).

Self-regulated learners choose the apt learning strategies consistent with the feedback they receive about the effectiveness of their academic performance as well as their skill (Zimmerman, 1990). Based on Vygotsky's study of individual's regulation process, Postholm (2011) referred to the social community as the departure point of individuals' regulations, a process that gradually will be internalized by the learners, thus becoming one of the individuals' skills. This signifies the important role of social context in self-instruction (Postholm, 2011). Attributional feedback exerts influence on self-regulated learning since it enhances learners' motivation, their sense of efficacy, and attainment (Schunk \& Zimmerman, 2003). Employing strategies is an inseparable component of self-regulated learning because using strategies provides learners with better management over information processing (Butler, 2002). Self-regulated learners evaluate their outcome consistent with the kind of strategy they employ (Butler, 2002).

Following Zimmerman's model (2000), Yesim, Sunger, and Uzuntiryaki (2009) proposed that teachers' self-regulation could be regarded as a dynamic process in which teachers could orient and keep their motivation, cognition, and strategies for effective teaching. The importance of applying self-regulated strategies in educational field is to the point that many scholars note that it is a fundamental part of effective teaching (e.g., Randi, 2004; Ghanizadeh, 2011; Ghonsooly \& Ghanizadeh, 2013). Empirical research documented that there was a significant relationship between EFL teachers' pedagogical success and their application of self-regulated strategies at their teaching environment (Monshi Toussi, Boori, \& Ghanizadeh, 2011). Research demonstrated statistically that applying self-regulated strategies could contribute to reduce teacher's burnout (Pietarinen, Pyhältö, Soini, \& Salmela-Aro, 2013; Doménech-Betoret \& Gómez Artiga, 2010; Ghanizadeh \& Ghonsooly, 2014). Professional burnout has been identified as a bodily as well as mental exhaustion in which the job performer does not have positive feelings toward people he/she contacts, he/she is not interested of his/her effective professional function and holds a negative career image of himself/herself (Maslach \& Leiter, 1982, as cited in Papastylianou, Kaila, \& Polychronopoulos, 2009).

The researchers of the current study attempted to explore the relationship between burnout sources and self-regulated strategies among EFL teachers of various EFL levels quantitatively and qualitatively. The researchers of the current study seek out to examine this association on the grounds of Randy's (2004) argument based on social-cognitive principles that proposes high-qualified teachers are self-regulated and as Pietarinen et al. (2013) documented those self-regulated teachers tend to have better professional and emotional well-being.

\section{Theoretical background}

\subsection{Self-regulation}

According to Bandura (1977) providing students with self-regulatory abilities resulted in their educational 
A mixed methods analysis of EFL teachers' self-regulated strategies and burnout

achievement as well as increasing lifelong learning (Young, 2005). Caprara et al. (2008) argued that learners' self-efficacy is crucial for their self-regulated learning. They stated some prominent features of self-efficacious students: when confronting with school tasks, self-efficacious students are confident in managing task difficulty, deal with difficulties as challenges, and devote more effort to accomplish their academic task which contributes to their learning improvement.

For developing learners' self-regulation, various teaching models have been introduced so far among which are the process-oriented education-adaptive learning (PRO-AL) developed by Boekaerts and Simons (1995) and the process-oriented teaching model proposed by Vermunt and Verschaffel (2000) (Oolbekkink-Marchand, Driel, \& Verloop, 2014). These frameworks introduced models following process-orientated approach to instruction. Such approach refers to management the learning process which requires teachers to be aware of applying strategies by students; for achieving this aim teachers' instruction must be consistent with process-oriented principles (Oolbekkink-Marchand, Driel, \& Verloop, 2014).

In their model, Boekaerts and Simons (1995) identified three steps for PRO-AL teaching: Instructor regulation, shared regulation, and student regulation. They stated that the differences between these steps are due to the amount of control that perform by instructor himself/herself, both instructor and student, and student alone. They argued that PRO-AL model is assumed to reach this aim that fosters and flourishes students' responsibilities. In the second model, the process-oriented teaching model proposed by Vermunt and Verschaffel (2000), the effective teaching is expected to foster students' learning as well as thinking strategies and increasing domain-specific information. Both models highlight the significance of the transition of learners' regulation of learning from instructor part to the students' part (Oolbekkink-Marchand, Driel, \& Verloop, 2014).

Another regulation is emotional regulation which relates to individuals' emotional as well as feelings expression (Sutton, 2004). Individuals regulate their emotions in two forms: cognitive reappraisal and expressive suppression (Gross \& John, 2003, as cited in Chang, 2013). Cognitive reappraisal refers to individuals' reassessment of problematic situations in order to diminish the probable unpleasant effects. Expressive suppression hinders present emotion-expressive behavior. In teacher education, emotional regulation is important in several respects, for example, by regulating emotions teachers think that they can achieve particular aims such as academic, cultural, instructional, and management goals (Sutton, 2004). This type of teachers emotional regulation is perceived as a sub-goal via which they can acquire their higher aims or "a means to an end". Sutton (2004) investigated the aims of emotional regulation on 30 teachers from middle school in USA and found that by applying emotional regulation they accomplish one or both of the following goals: effective teaching and idealized emotion of an instructor.

\subsection{Burnout}

Pine (1993, as cited in Dworkin, 2001, p. 70) viewed burnout "as an existential crisis, linked to a sense of meaninglessness. That is to extent that professionals come to incorporate their work into their self-image, conditions that diminish the personal assessment of the value of that work likewise diminish the assessment of self-worth". From these psychological issues, research on burnout treatment suggests various options ranging from stress control to holistic well-being practices such as yoga, taking naps, and many others (Dworkin, 2001).

Simbula and Guglielmi (2010) examined another line of investigation: the probable role of inefficacy beliefs of burnout dimensions and the establishment of depersonalization and cynicism as two different subscales of burnout on Italian teachers. To reach their goal, they divided participants into two main groups. Group 1 consisting of 290 teachers received the original version of MBI (the items indicating emotional exhaustion, depersonalization and cynicism were articulated negatively and the items indicating personal accomplishment were articulated positively). Group 2 including 225 teachers were distributed the version of MBI in which all items representing emotional exhaustion, depersonalization, cynicism, and personal accomplishment were articulated negatively. Their findings documented that compared with efficacy beliefs, inefficacy beliefs had a 
stronger link with other burnout components: emotional exhaustion, depersonalization, cynicism. Moreover, their result gaining by partial disaggregation method showed that a four-factor model with depersonalization and cynicism as detached components had a better fit than a three-factor model in which depersonalization and cynicism were integrated into one factor.

In another study, Pishghadam and Sahebjam (2012) realized that there was a significant relationship between Iranian EFL teachers' personality, emotional intelligence, and burnout. More specifically, their results indicated that for emotional exhaustion neuroticism as well as extroversion, for depersonalization intrapersonal scale of emotional intelligence and agreeableness, and finally, for personal accomplishment interpersonal scale and conscientiousness were the best predictors respectively. Moneta (2011) carried out a research on 226 university students to explore the relationship between the need for achievement, burnout, and intention to leave. In her study she realized that the need for achievement directly suppressed the experience of three components of burnout. Research revealed that among the components of burnout, emotional exhaustion has surpassed depersonalization and reduced personal achievement in that it is a better predictor of professional performance, job attitudes, and workers' behaviors (Tsouloupasa, Carsona, Matthewsb, Grawitchc, \& Barber, 2010). In a recent review on teacher burnout, Ghanizadeh and Jahedizadeh (2014) reported that emotional exhaustion is the prime indicator of teacher burnout and is directly linked to negative exchanges with students and teachers' personal experiences and characteristics. It has also been demonstrated that various organizational factors such as lack of public admiration and lack of regard from administrators produce teacher burnout (Gavish \& Freidman, 2010).

\subsection{Research on self-regulation and burnout}

Doménech-Betoret and Gómez Artiga (2010) stated that teachers used coping strategies in stressful situations. Coping refers to individual's behavior as well as thought that they apply in emotional challenging situations to manage and control their feelings and it consists of two types: emotion-focusing coping and problem-focused coping (Folkman \& Lazarus, 1987, as cited in Chang, 2013). Whilst the former refers to decreasing undesirable emotions by treating the challenging emotion itself, the latter relates to managing the problem. In addition to these copings, another model was introduced as proactive copings. Proactive copings refer to "efforts to build up general resources that facilitate promotion of challenging goals and personal growth" (Greenglass, 2002, p. 38, as cited in Chang, 2013). These proactive copings provide individuals to predict manageable strategies before tackling with problems (Chang, 2013).

In teacher education, proactive copings provide teacher to anticipate the challenging interactions and employ effective approach to deal with difficulties (Chang, 2013). Ghanizadeh and Ghonsooly (2014) designed and validated an EFL teachers' attribution questionnaire and investigated the link between teachers' attribution, self-regulation, and burnout. Their findings documented the contribution of internal and controllable attribution to teachers' self-regulatory strategies and also it was found that teachers' with external and uncontrollable attributions were more susceptible to experience burnout. In addition to job-related stress factors, research on burnout sources revealed that individual and interactional factors show a considerable role on creating burnout among teachers (Brenninkmeijer, Vanyperen, \& Bunnk, 2001).

To the researchers' best knowledge no study has been done to date to explore qualitatively the relationship between Iranian EFL teachers' self-regulated strategies and their burnout sources so the followings research questions have been explored in this study.

$>$ Is there any significant relationship between burnout depletion and the use of self- regulated strategies among Iranian EFL teachers?

$>\quad$ Which burnout sources would EFL teachers confront in different English learning levels?

$>\quad$ Which self-regulated strategies do EFL teachers use across EFL levels? 


\section{Method}

\subsection{Participants}

The participants of the present study consisted of 125 EFL teachers selected based on convenience sampling among EFL teachers teaching in foreign language institutes in Mashhad. Their age varied from 24 to 57 years old and their teaching experience ranged from 3 to 34 years. Out of 125 teachers, 21 teachers held Ph.D. or were candidates of Ph.D. of TEFL. 87 held M.A. degree or were M.A. students, and the rest had B.A. Two participants did not identify their educational level. All the participants' mother language was Persian.

\subsection{Instrumentation}

The participants of the current study were asked to complete two questionnaires:

$>\quad$ Teacher Self-Regulation Scale (TSRS)

$>\quad$ Maslach Burnout Inventory (MBI)

Teacher Self-Regulation Scale (TSRS) - To measure teacher self-regulation, the researchers applied the Teacher Self-Regulation Scale (TSRS), designed by Yesim et al. (2009). This scale is based on the model proposed by Zimmerman' s self-regulation. It comprised 40 items using six-point Likert scale ranging from (6) "strongly agree" to (1) "strongly disagree". Scores on this test represents teachers' degree of self-regulation as teachers own self-regulated strategies which they apply in classrooms. This test includes 9 factors: Goal setting, Intrinsic interest, Performance goal orientation, Mastery goal orientation, Self-instruction, Emotional control, Self-evaluation, Self-reaction, and help seeking. In this study, the total reliability of the scale, estimated via Cronbach's alpha, was 0.86 .

Maslach's Burnout Inventory (MBI) - To assess teachers' level of burnout, the Maslach's Burnout Inventory (MBI) (Maslach \& Jackson, 1986) was applied. This test consists of 22 questions: 9 items to measure "emotional exhaustion", 8 items for "reduced personal accomplishment" and 5 to assess "depersonalization". The items are scored in two ways: according to the frequency in which the participants' burnout levels are scored on a 7- point frequency scale ranging from (0) "never" to (6) "everyday". The English teachers participating in this study were required to complete the inventory based on this 7-point scale. The second way is based on the intensity in which the items are scored on 8-point scale ranging from (0) "none" to (7) "very much". The higher values in both frequency and intensity ways show that the teachers experience the burnout factors. In this study, the first way of scoring (frequency model) was used. In this study, the total reliability of this scale, estimated via Cronbach's alpha, was 0.92 .

\subsection{Interview}

A semi-structured interview was held in order to investigate the participants' source of burnout, their reactions, and their pattern of self-regulated strategies in each level.

\subsection{Data collection}

The process of data collection started in September 2013 and completed in July 2014. The researchers of the present study collected data in convenience sampling at three phases. In phase one, the participants were distributed Teacher Self-regulation Scale (TSRS) as well as Maslach Burnout Inventory (MBI) to complete. After they filled in the questionnaires, the researchers started the phase two; in phase two they selected those participants who got high score in TSRS and low scores in MBI. Finally, in phase three, a semi-structured interview was held with these teachers in order to find the burnout sources and pattern of self-regulated strategies in various EFL levels. For increasing the validity of the qualitative part of this study, the researchers used a 
Royaei, N., Ghonsooly, B., \& Ghanizadeh, A.

grounded theory. Grounded theory refers to the continuing collecting the data until the required association between concepts are saturated (Dorney, 2004). To accomplish this aim, the researchers collected 125 EFL teachers and repeated the process of phase one for choosing the more self-regulated and less burnout experienced teachers. 40 teachers were identified for this study and then they were invited to take part in an interview. After interviewing with $40 \mathrm{EFL}$ teachers, the researchers found a particular burnout sources among participants that will be discussed in details in following section. Before administering the aforementioned questionnaire, the EFL teachers participats were assured that their personal information would be kept confidential.

\subsection{Data Analysis}

In order to analyze the data, the researchers applied SPSS 20 program as well as interviews. To explore whether there was any correlation between self-regulated strategies and burnout, a Pearson-product moment correlation was employed. Second, by applying Stepwise regression analysis the researchers realize that which subcomponent of self-regulated strategies was the best predictor of burnout. At the end, interviews were analyzed in order to identify burnout sources and the kind of self-regulated strategies applied in each EFL level.

\section{Results}

\subsection{Results of the Quantitative Part}

\section{Table 1}

The descriptive statistics for the TSRS and MBI

\begin{tabular}{lccccc}
\hline \multicolumn{1}{c}{ Scale } & $N$ & Minimum & Maximum & Mean & $S D$ \\
\hline TSRS & 125 & 142 & 232 & 194.00 & 18.51 \\
MBI & 125 & 22 & 110 & 67.20 & 19.03 \\
\hline
\end{tabular}

To examine the relationship between teachers' self-regulation and their burnout, the Pearson Product-moment correlation was applied. This revealed a significant correlation between self-regulation and burnout depletion $(\mathrm{r}=-.60, p<.05)$ as shown in Table 2.

\section{Table 2}

The correlation between self-regulation and burnout

\begin{tabular}{lc}
\hline \multicolumn{1}{c}{ TSRS Factor } & Burnout \\
\hline Goal setting & $-.56^{* * *}$ \\
Intrinsic interest & $-.36^{* *}$ \\
Performance goal orientation & $-.35^{* *}$ \\
Mastery goal orientation & $-.17^{* *}$ \\
Self-instruction & $-.20^{* *}$ \\
Emotional control & $-.40^{* *}$ \\
Self-evaluation & $-.43^{* *}$ \\
Self-reaction & $-.39^{* *}$ \\
Help seeking & $-.34^{* *}$ \\
SR total & $-.60^{* *}$ \\
\hline Note. ${ }^{* *}$ Indicates the existence of the significant relationship at the level of 0.01
\end{tabular}

To find the best predictor of burnout depletion, the researchers conducted the regression analysis with a Stepwise method. The results revealed that goal setting was the best predictor and could account for about .31 $(p<0.5)$ of the variance in burnout depletion. As Table 3 revealed, that goal setting was the best predictor and could account for about $.31(p<0.5)$ of the variance in burnout depletion.

\subsection{Results of the Qualitative Part}

For analyzing the interviews, they were recorded and they were transcribed. For better investigation, the 
A mixed methods analysis of EFL teachers' self-regulated strategies and burnout

researchers assigned numerical code for each burnout sources and also assigned an alphabetic code for each type of self-regulated strategies. Then the researchers calculated the frequency of each burnout sources and pattern of self-regulated strategies. Delving into teachers' experiences revealed that there were a number of situations that caused burnout. It should be highlighted that almost all teachers emphasized that burnout was a short-term syndrome.

Table 3

Stepwise regression predicting burnout

\begin{tabular}{ccccc}
\hline Predictor & $R$ & $R^{2}$ & $F$ & $B$ \\
\hline Goal setting & .563 & .317 & 57.153 & -.563 \\
\hline
\end{tabular}

Table 4

Burnout sources in various EFL level

\begin{tabular}{ll}
\hline \multicolumn{1}{c}{ EFL Level } & \multicolumn{1}{c}{ Burnout Sources } \\
\hline Elementary and intermediate & classroom management, interactional style, lack of \\
& learners' motivation \\
Advanced & learners' high expectations \\
\hline
\end{tabular}

Table 5

Self-regulated strategies in various EFL levels

\begin{tabular}{|c|c|}
\hline EFL Level & Pattern of Self-regulated Strategies \\
\hline Elementary & motivational as well as cognitive strategies \\
\hline Advanced & motivational, meta-cognitive, and cognitive strategies \\
\hline
\end{tabular}

\subsection{Variations of teachers' burnout}

Burnout sources in elementary and intermediate levels - A qualitative analysis of teachers' experiences identified the following causes of burnout in elementary and intermediate levels:

Classroom management skills and interactional style: because there were students who had external motivation (e.g. their parents had sent them to learn English); such students did not follow the learning stream as motivated learners. They complained about task difficulty, ignored classroom productive participant, and lacked motivation and interest in communicating with teachers.

Burnout sources in advanced levels - A qualitative analysis of teachers' experiences identified the following causes of burnout though rarely, in advanced level:

Learners' high expectation of themselves to achieve a good deal of accomplishments; "In advanced levels learners try to be more competent in comparison with intermediate learners. As an example, one teacher articulated that it is sensible because learners who become advanced learners have enough motivation to continue their learning on a good pace. But they need a model for some tasks such as formal writing. We try to turn learners' attention to develop this skill gradually. For achieving this aim we give them the required appropriate instructions as well as apt strategies for managing their performances.

\subsection{Variations of teachers' self-regulated strategies}

Teachers' self-regulated strategies at elementary and intermediate levels - Self-regulated teachers use many strategies in their instructions (Yesim et al., 2009). This study documented qualitatively that due to the learners' needs, each level required particular strategies. In the current study, in beginning levels EFL teachers applied motivational and cognitive strategies to keep learners on pace. It seems plausible given that when 
learners start learning a foreign language they need a warm atmosphere to have the ability to communicate freely in their interactions in foreign language more than advanced learners. Their first communications are of highly importance for learners in that these interrelationships are fixed in their minds and can be supposed as an indicator of their abilities that can contribute to encourage or disappoint them from learning a foreign language. It is a common sense that when learners feel capable of learning another language, they think that they are more intelligent than the students who are not successful. As the result, they have a sense of pride.

Although research revealed that intelligence is not the only predictor of learning a language and there are many environmental as well as other individual factors that intervene in learners' accomplishment (Brown, 2007), this feeling existed among young learners. Another important aspect that almost all teachers admitted in this study is that showing positive emotions help learners to have a positive image of teaching profession and their learning process.

They stated that learners in these levels need a feeling of being supported by their teachers. As an example, one of the teachers stated: "In such situations I show more positive emotions in my interactions with learners, particularly with less motivated and/or weak learners. They trust me to guide and help them whenever they feel unable to be successful as much as their classmates. For example, last week I asked two of my learners to practice dialogue. One of these students was weak in communicative skills and he made some mistakes. During his attempts to continue conversation with his friend, he was looking at me to get him some clues. His eyes told me "Teacher, please help me!" My reaction to this massage was smiling and told him what would you do in this supposed situation? He said something in a very grammatically simple sentence and with too much stress. I said I like and appreciate your reactions more than the conversation character's ones. He was surprised and said really! I smiled again and replied "Yes, really!" From that time he tried to express his own ideas and behaviors in real situations. And what happened at the end? Little by little he found much confidence and enjoyed to have a voice in class".

Theoretically analyzing the text, this teacher seems to dedicate a role of agency to his learner to find more motivation to accomplish his leaning tasks more quickly. This teacher, in fact, used emotion regulation strategy to encourage learner for better performance instead of showing anger or ignorance in such stressful situations. Research showed that EFL beginner learners are dependent on their teachers (Richards \& Rodgers, 2001). Feeling of being supported is highlighted in stressful conditions as Hargreaves (1998) argued that an effective teaching required positive emotions.

Teachers' self-regulated strategies in advanced levels - The results demonstrated that in advanced levels less motivational and more meta-cognitive strategies were used. The interview findings showed that when learners become advanced learners they have many expectations of themselves; for example to be able to speak English well, to translate well, and to have a great repertoire of vocabulary. Following is an extract of interview with an advanced level teacher:

"In our academic sessions for evaluating our career we conclude that some students pass levels without encountering diminishing interest and particular problems and enjoy flourishing their language learning potentialities. When we identified these successful students we found that they were those who had great accountability of their learning process". The interviewed participants of current study confirmed that because they have received great understanding of learners' individual factors, sometimes they feel it is necessary to apply their own teaching techniques. As a consequence, when they feel a notable problem they try to control and manage the challenging situations to get the optimal results.

\section{Discussion}

The current study shed lights on exploring the relationship between EFL teachers' burnout and their self-regulated strategies in Iranian context. In line with our hypothesis, our findings documented statistically that there was a negative significant relationship between these two constructs. In other words, teachers who were 
A mixed methods analysis of EFL teachers' self-regulated strategies and burnout

more self-regulated in their professional setting confronted with burnout less than teachers who were not self-regulated. It can be stated that self-regulated teachers are proactive (Pietarinen et al., 2013). This proactivity allows them to anticipate which factors prevent their professional development and as a consequence, they can manage the problematic situations (Chang, 2013).

Research demonstrated that teachers' self-regulation exerts prominent influence on learners' self-regulation (van Beek, de Jong, Minnaert, \& Wubbels, 2014); for example: Becker, Goetz, Morger, and Ranellucciwhen (2014) stated that when teachers presented comprehensive and obvious explanations during instruction, they enriched learners' control appraisal as well as value appraisal; control appraisal refers to learners' expectations that they hold about their academic aptitudes that may contribute to their achievements and value appraisal refers to learners' evaluations of the relevance of task. These self-regulated students have better achievements (Zimmerman, 1998), and these successful students can encourage teachers for better professional functioning and as a result, prevent teacher burnout (Brenninkmeijer et al., 2001).

With respect to the second research question, detecting the best predictors, it should be mentioned that the findings obtained via Stepwise Regression Analysis confirmed those in correlational analysis. Among the components of self-regulated strategies, goal setting was the best predictor of burnout. In other words, EFL teachers who established goals for their teaching and attempted to accomplish them would be rarely at the risk of burnout. Because self-regulation is a goal-oriented process (Zimmerman \& Martinez-Pons, 1990) and teaching profession requires "on-going practice of reflection on practice and underlying assumptions" (Borko \& Putnam, 1998, p. 3). Self-regulated teachers have dynamic evaluation of their functioning (Yesim et al., 2009), so they are expected to experience burnout less than those who are not self-regulated.

Regarding different English language learning levels, our findings via interview analysis showed that although EFL teachers tended to apply various self-regulated strategies, motivational strategies were reported consistently across all levels. This result is consistent with Pintrich's (1991) argument that motivational perspectives are dominant in every component of the teaching and learning process and, therefore, an understanding of the nature of motivation within the school context is essential (as cited in Chang, 2013). From an applied perspective, the findings of the current study documented the extension of pervious findings that equipping teachers with a toolbox of self-regulated strategies can result in preventing them from experiencing different burnout sources (e.g. Pietarinen et al., 2013).

\subsection{Implications}

This study contributes to current teacher education research by filling some gaps in our understanding of what pattern of self-regulated strategies were applied in perceived burnout situations by EFL teachers. In fact, the current study was addressed to investigate the burnout sources that EFL teachers confronted in elementary, intermediate, and advanced levels and the pattern of self-regulated strategies they used in order to manage and diminish those burnout sources in Iranian EFL language institutes. The result of the qualitative analysis showed that EFL teachers used a variety of self-regulated strategies; motivational, cognitive, and meta-cognitive ones, but the frequency and distribution of each strategy were inconsistent across various levels. In elementary levels, learners need more enjoyment, excitement, and warm atmosphere to become engaged in performing learning tasks. These features encourages teachers to apply more motivational strategies, including emotion regulation. This in turn appears to contribute to teachers' emotional well-being which would prevent emotional exhaustion.

\section{References}

Barnard-Brack, L., Lan, W. Y., \& Paton, V. O. (2010). Profiles in self-regulated learning in the online learning environment. International Review of Research in Open and Distance Learning, 11(1), 61-80.

Becker, E.S., Goetz, T., Morger, V., \& Ranellucci, J. (2014). The importance of teachers' emotions and instructional behavior for their students' emotions - An experience sampling analysis. Teaching and 
Royaei, N., Ghonsooly, B., \& Ghanizadeh, A.

Teacher Education, 43, 15-26. http://dx.doi.org/10.1016/j.tate.2014.05.002

Borko, H., \& Putnam, R. (1998). Professional development and reform-based teaching: Introduction to the theme issue. Teaching and Teacher Education, 14(1), 1-3.

Brenninkmeijer, V., VanYperen, Nico.W., \& Buunk, Bram P. (2001). I am not a better teacher, but others are doing worse: Burnout and perceptions of superiority among teachers, Social Psychology of Education, 4, 259-274. http://dx.doi.org/10.1023/A:1011376503306

Brown, H. D. (2007). Principles of language learning and teaching (5th ed.). NY: Pearson Education, Inc.

Butler, D. L. (2002). Individualizing instruction in self-regulated learning, Theory into Practice, 41(2), 81-92. http://dx.doi.org/10.1207/s15430421tip4102_4

Caprara, G. V., Fidar, R., Vecchione, M., Del Bove, G., Vecchio, G. M., Barbaranelli, C., \& Bandura, A. (2008). Longitudinal analysis of the role of perceived self-efficacy for self-regulated learning in academic continuance and achievement. Journal of Educational Psychology, 100, 525-534. http://dx.doi.org/10.1037/0022-0663.100.3.525

Chang, M.-L. (2013). Toward a theoretical model to understand teacher emotions and teacher burnout in the context of student misbehavior: Appraisal, regulation and coping. Motivation Emotion, 37, 799-817. http://dx.doi.org/10.1007/s11031-012-9335-0

De Corte, E., Depaepe, F., Op 't Eynde, F., \&Verschaffel, L. (2011). Students' self-regulation of emotions in mathematics: an analysis of meta-emotional knowledge and skills. ZDM Mathematics Education, 43, 483-495. http://dx.doi.org/10.1007/s11858-011-0333-6

Doménech Betoret, F., \& Gómez Artiga, A. (2010). Barriers perceived by teachers at work, coping strategies, self-efficacy and burnout. The Spanish Journal of Psychology, 13(2), 637-654. http://dx.doi.org/10.1017/S1138741600002316

Dornyei, Z. (2007). Research methods in applied linguistic. Oxford University Press.

Dworkin, A. G. (2001). Perspectives on teacher burnout and school reform. International Education Journal, 2(2), 69-78.

Gavish, B., \& Friedman, I. A. (2010). Novice teachers' experience of teaching: a dynamic aspect of burnout, Social Psychology Education, 13, 141-167. http://dx.doi.org/10.1007/s11218-009-9108-0

Ghanizadeh, A. (2011). An investigation into the relationship between self-regulation and critical thinking among Iranian EFL teachers. The Journal of Technology \& Education, 5(3), 213-221.

Ghanizadeh, A., \& Ghonsooly, B. (2014). A tripartite model of EFL teacher attributions, burnout, and self-regulation: toward the prospects of effective teaching. Educational Research in Policy and Practice, 13, 145-166. http://dx.doi.org/10.1007/s10671-013-9155-3

Ghanizadeh, A., \& Jahedizadeh, S. (2015). Teacher burnout: A review of sources and ramifications. British Journal of Education, Society, and Behavioural Sciences, 6(1), 24-39. http://dx.doi.org/10.9734/BJESBS/2015/15162

Ghonsooly, B., \& Ghanizadeh, A. (2013). Self-efficacy and self-regulation and their relationship: a study of Iranian EFL teachers. The Language Learning Journal, 41 (1), 68-84, http://dx.doi.org/10.1080/09571736.2011.625096

Hargreaves, A. (1998). The emotional practice of teaching. Teaching and Teacher Education, 14(8), 835-854. http://dx.doi.org/10.1016/S0742-051X(98)00025-0

Maslach, C., \& Jackson, S. E. (1986). Maslach burnout inventory. Palo Alto, CA: Consulting Psychologist Press.

Moneta, G. B. (2011). Need for achievement, burnout, and intention to leave: Testing an occupational model in educational settings. Personality and Individual Differences, 50, 274-278. http://dx.doi.org/10.1016/j.paid.2010.10.002

Monshi Toussi, M. T., Boori, A. A., \& Ghanizadeh, A. (2011). The role of EFL teachers' self-regulation in effective teaching. World Journal of Education, 1(2), 39-48. http://dx.doi.org/10.5430/wje.v1n2p39

Oolbekkink-Marchand, H. W., Van Driel, J. H. \& Verloop, N. (2014). Perspectives on teaching and regulation of learning: a comparison of secondary and university teachers. Teaching in Higher Education, 19(7), 799-811. http://dx.doi.org/10.1080/13562517.2014.934342

Papastylianou, A., Kaila,M., \& Polychronopoulos, M. (2009). Teachers' burnout, depression, role ambiguity and 
A mixed methods analysis of EFL teachers' self-regulated strategies and burnout

conflict. Social Psychology of Education, 12, 295-341. http://dx.doi.org/10.1007/s11218-008-9086-7

Pietarinen, J , Pyhältö, K., Soini, T., \& Salmela-Aro, K. (2013). Reducing teacher burnout: A socio-contextual approach. Teaching and Teacher Education, 35, 62-72. http://dx.doi.org/10.1016/j.tate.2013.05.003

Pishghadam, R., \& Sahebjam, S. (2012). Personality and Emotional Intelligence in Teacher Burnout. The Spanish Journal of Psychology, 15(1), 227-236. http://dx.doi.org/10.5209/rev_SJOP.2012.v15.n1.37314

Postholm, M. B. (2011). Self-regulated learning in teaching: Students' experiences, Teachers and Teaching: Theory and Practice, 17(3), 365-382.

Randi, J. (2004). Teachers as self-regulated learners. Teachers College Record, 106, 1825-1853. http://dx.doi.org/10.1111/j.1467-9620.2004.00407.x

Richards, J.C., \& Rodgers, T. (2001). Approaches and methods in language teaching (5th ed.). Cambridge University Press. http://dx.doi.org/10.1017/CBO9780511667305

Schunk, D. H., \& Zimmerman, B. J. (2003). Self-regulation and Learning. In W. M. Reynolds \& I. B. Miller (Eds), Handbook of psychology (pp.59-78). New Jersey, NJ: John Wiley \& Sons. Inc. http://dx.doi.org/10.1002/0471264385.wei0704

Simbula, S., \& Guglielmi, D. (2010). Depersonalization or cynicism, efficacy or inefficacy: What are the dimensions of teacher burnout? European Journal of Psychology Education, 25, 301- 314. http://dx.doi.org/10.1007/s10212-010-0017-6

Sutton, R. E. (2004). Emotional regulation goals and strategies of teachers. Social Psychology of Education, 7, 379-398. http://dx.doi.org/10.1007/s11218-004-4229-y

Tsouloupas, C. N., Carson, R. L., Matthews, R., Grawitch, M. J., \& Barber, L. K. (2010). Exploring the association between teachers' perceived student mis-behaviour and emotional exhaustion: The importance of teacher efficacy beliefs and emotion regulation. Educational Psychology, 30(2), 173-189. http://dx.doi.org/10.1080/01443410903494460

Van Beek, J. A., de Jong, F. P. C. M., Minnaert, A. E. M. G., \& Wubbls, Th. (2014). Teacher practice in secondary vocational education: Between teacher-regulated activities of student learning and student self-regulation. Teaching and Teacher Education, 40, 1-9. http://dx.doi.org/10.1016/j.tate.2014.01.005

Yesim, C. A., Sungur, S., \& Uzuntiryaki, E. (2009). Teacher self-regulation: Examining a multidimensional construct. Educational Psychology, 29(3), 345-356. http://dx.doi.org/10.1080/01443410902927825

Young, M. R. (2005). Journal of Marketing Education, 27(1), 25-40. http://dx.doi.org/10.1177/0273475304273346

Zimmerman, B. J. (1990). Self-regulated learning and academic achievement: An overview. Educational Psychologist, 25(1), 3-17. http://dx.doi.org/10.1207/s15326985ep2501_2

Zimmerman, B. J., \& Martinez-Pons, M. (1990). Student differences in self-regulated learning: Relating grade, sex, and giftedness to self-efficacy and strategy use. Journal of Educational Psychology, 82(1), 51-59. http://dx.doi.org/10.1037/0022-0663.82.1.51

Zimmerman, B. J. (1998). Academic studying and the development of personal skill: A self-regulatory perspective. Educational Psychologist, 33(2/3), 73-86. http://dx.doi.org/10.1080/00461520.1998.9653292

Zimmerman, B. J. (2008). Investigating self-regulation and motivation: Historical background, methodological development, and future prospects. American Educational Research Journal, 45(1), 166-183. http://dx.doi.org/10.3102/0002831207312909 
Royaei, N., Ghonsooly, B., \& Ghanizadeh, A. 